\title{
IS THE UNAFFECTED SIDE OF STROKE PATIENTS ACTUALLY NORMAL?
}

\section{Soumiya Selvarajan ${ }^{1}$, Gajanan Bhalerao *2, Ashok K. Shyam ${ }^{3}$, Parag Sancheti ${ }^{4}$.}

${ }^{1}$ B.P.Th, Sancheti Institute College of Physiotherapy, Pune, Maharashtra, India.

${ }^{2}$ M.P.Th, Sancheti Institute College of Physiotherapy, Pune, Maharashtra, India.

${ }^{3}$ MS Ortho, Research Officer- Sancheti Institute for Orthopedics and Rehabilitation, Pune, Maharashtra, India.

${ }^{4}$ MS Ortho, Chairman- Sancheti Institute for Orthopedics and Rehabilitation, Pune, Maharashtra, India.

\section{ABSTRACT}

Objective: The aim of the study was to find how affected is the unaffected side of stroke population.

Methods: 20 participants were recruited who met the inclusion criteria of more than 3-month first time unilateral both male and female stroke patients of age group 40-60 years were assessed and evaluated for the 3 parameters using grip dynamometer, peg board and reaction time machine respectively and compared it to the normal healthy age, gender and dominance matched individuals.

Results: The unaffected side of stroke patients was significantly affected in gross motor strength, fine motor dexterity, reaction time audio and visual when compared to normal population.

Conclusion: There are significant motor deficits seen in the unaffected side of stroke patients.

KEY WORDS: Hemiplegia, Gross Motor Strength, Fine Motor Strength, Reaction Time.

Address for correspondence: Dr. Gajanan Bhalerao, Sancheti Institute College of Physiotherapy, Shivaji Nagar, Pune-5, Maharashtra, India. E-Mail: gajanan-_bhalerao@yahoo.com

Access this Article online

Quick Response code

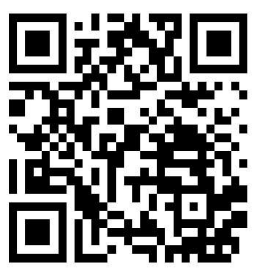

DOI: $10.16965 /$ ijpr.2019.141

Journal Information

International Journal of Physiotherapy and Research

ICV for 2016 ISSN (E) 2321-1822 | ISSN (P) 2321-8975

86.93 https://www.ijmhr.org/ijpr.html

DOI-Prefix: https://dx.doi.org/10.16965/ijpr

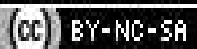

\section{Article Information}

Received: 12 Apr 2019

Peer Review: 12 Apr 2019

Revised: None
Accepted: 22 Apr 2019

Published (O): 20 Jun 2019

Published (P): 11 Aug 2019

\section{INTRODUCTION}

Stroke is a disease that affects the arteries leading to and within the brain. It is the fourth leading cause of death and a leading cause of disability. A stroke occurs when a part of the brain cannot get the blood it needs because of the blood supply being blocked or ruptured and so the brain cells die. As brain is an extremely complex organ that controls various body functions. If a stroke occurs in the region that controls a body function won't work as it should. However, because one side of the brain controls the opposite side of the body, a stroke affecting one side will result in neurological complications on the side of the body it affects [1]. Many researchers have conducted studies on the affected side of the body and established the fact. Whereas very few of us know that there are sensorimotor deficits seen in the non-affected side of the body as well.

Motor deficits after stroke are often evident on the side of the body that is contralateral to the side of brain damage. There is increasing evidence, however, that motor performance of the upper extremity (UE) on the side ipsilateral 
to the brain damage is also affected [2].

A unilateral cerebral hemispheric stroke rarely produces ipsilateral gestural disturbances, and these are less obvious than the contralateral ones. However, Pohl et al [2], Yelnik et al [3] showed that patients with parietal lesions have many ipsilateral motor disturbances since then. Most of the tasks used in our daily life, requires a certain reaction time, rhythm or speed. Thus, simple and complex visual-motor reaction times increase in cases of both right and left ipsilateral hemispheric lesion [4-6] while the left hemisphere seems to be dominant in studies of reaction time during multiple-choice task.

The need of the study was to identify the motor control deficits of the unaffected side in stroke patients when compared to normal healthy age matched individuals and to emphasize on effective and efficient rehabilitation of stroke patients of both the sides.

\section{METHODOLOGY}

The study was initiated following the approval of Institutional Review Board. Purposeful Sampling was done. Inclusion criteria was patients with first time unilateral cerebral stroke more than 3 months of age ranging from 40-60 years both male and female patients. Exclusion criteria was patients with hemineglect hemianopia and apraxia which were ruled out with few tests. 40 subjects ( 20 hemiplegic (stroke) and 20 healthy individuals age sex and dominance matched individuals) were recruited. The subjects were recruited through purposive sampling. Subjects meeting the inclusion criteria were evaluated to show no important visual perceptual deficits (minimum score of 24/ 36 on the Motor Free Visual Perceptual Test [7-9] and a minimum score of 26/35 on the Bell Test [10] to eliminate the presence of visual hemineglect), and show no important cognitive deficits (minimum result of $80 / 100$ on the Modified Mini-Mental State Examination [11-13] they were explained about the research and consent was taken for the same. Subjects of healthy population were recruited by matching age, gender, dominance of stroke population and were consented about the research and all three parameters was assessed in the same way and values were recorded.

\section{Reaction time using reaction time machine:}

Subjects were explained about the reaction time machine and that it is used to measure a quantitative value to how fast a person reacts/ feedback to auditory and visual stimulus. Reaction time was measured for both affected and unaffected side of the body, but the values of only unaffected side was considered. A trial round was compulsorily given to all subjects. Values were recorded of three rounds and average of the three values was used to compare.

Gross motor [14] using hand held dynamometer [15] : Subjects were made to sit on a chair with the unaffected upper extremity at resting position of shoulder adducted and externally rotated to 90 degrees and elbow bend to 90 degrees and dynamometer was held in hand with wrist in neutral and 3 values were taken with a break of 30 seconds after every value and the best of the three was considered to compare.

Fine motor using nine-hole peg board test: Peg board was placed in front of the subject at their waist level and were instructed to remove the pegs and place them again how many ever times possible in 30 seconds and that only one peg can be removed at one time and similarly one peg to be placed in the board at one time with unaffected extremity only.

\section{RESULTS}

\begin{tabular}{|c|c|c|c|}
\hline Parameters & Normal & Stroke & P value \\
\hline Fine motor dexterity & $24.35( \pm 1.41)$ & $19.9( \pm 1.41)$ & 0 \\
\hline Gross motor strength & 23.85 & $20.2( \pm 4.24)$ & 0 \\
\hline Reaction time visual & $1.63( \pm 0.49)$ & $2.74( \pm 0.46)$ & 0 \\
\hline Reaction time auditory & $2.17( \pm 0.56)$ & $2.36( \pm 0.33)$ & 0 \\
\hline
\end{tabular}

\section{DISCUSSION}

Significant difference was observed between the two groups for gross motor, fine motor and reaction time. The sensorimotor deficits observed in the unaffected extremities can be considered due to disruption of output from the damaged hemisphere [18].

It is possible that a lesion in one hemisphere resulting from a vascular cause interrupts corticobulbar and corticoreticular projections and consequently affects subcortical structures 
involved in motor control [19]. Therefore, the integrity of these descending pathways is necessary to achieve motor performance on the unaffected side.

However, the other view can be that the reduction of motor inhibition expressed as of the unmasking of inhibited pathways rather than a sign of restorative change to compensate for the motor deûcit [20]. That this abnormal motor inhibition may be non-speciûc is suggested by the fact that it did not correlate with the different degree of motor involvement between patients. The ûndings agree with the previous studies $[20,21]$, which showed that the presence of ipsilateral motor evoked potentials after stimulation of the unaffected hemisphere was associated with poor motor outcome. Patients with good motor recovery showed a dramatic decrease in excitability over the unaffected hemisphere with a return to normal inhibition values and the persistence of an abnormal excitability over the affected hemisphere. The presence of abnormal excitability over the unaffected hemisphere was associated with poor motor recovery [22].

It is also possible that the weakness on the paretic side interferes with the performance of movement on the unaffected side. For reaction time the nature of this task being complex involves both hemispheres as great sensorimotor interaction is needed. In healthy controls, involvement of ipsilateral motor areas is greater with more complex movements. The increased involvement of ipsilateral premotor cortex in simple movements of an impaired limb could just reflect the relative difficulty of such movements. The timing of the interference effects of ipsilateral motor cortex during the simple task in patients is like that observed for the more complex task reaction time in healthy controls [19].

Involvement of ipsilateral motor cortex was greatest in the more impaired patients. Therefore, the present results cannot be interpreted as showing that the undamaged premotor cortex is functionally substituting for the injured contralateral motor system in a complete and simple way. Although greater injury produces greater impairment, it also provokes a greater adaptive response. Although increased use of ipsilateral motor cortex does not enable complete recovery in the most impaired patients, it is likely that it enables greater recovery than would have been possible otherwise [23].

Few studies even showed that patients with good motor recovery showed a dramatic decrease in excitability over the unaffected hemisphere with a return to normal inhibition values and the persistence of an abnormal excitability over the affected hemisphere. The presence of abnormal excitability over the unaffected hemisphere was associated with poor motor recovery [23].

The motor areas of the hand muscles of both hemispheres are abnormally reduced in the early period after stroke and depends on the functional recovery. The main ûnding is that the unaffected hemisphere showed a return to normal values in patients with signiûcant motor recovery, while it remained abnormal in the unaffected hemisphere in patients with poor motor recovery [23]. Hence it is important to emphasize on rehabilitation of both sides in a stroke patient.

\section{CONCLUSION}

This study concludes that there are significant motor control deficits on the unaffected side of stroke patients when compared to normal healthy age, gender and dominance matched individuals.

\section{ACKNOWLEDGEMENTS}

We would take this opportunity to thank Mrs. Dhara Kapoor and Mrs. Rachana Dabadghav Research co-ordinator for their support and guidance. I extend my gratitude to all teachers, my friends and participants of this study who voluntarily participated in the study.

\section{Conflicts of interest: None}

\section{REFERENCES}

[1]. Amytis Towfighi, Jeffrey L. Saver. Stroke Declines from Third to Fourth Leading Cause of Death in the United States. Stroke. Jul 2011;42:2351-2355.

[2]. P.S. Pohl et al. Sensory-motor control in the ipsilesional upper extremity after stroke. NeuroRehabilitation 1997;9:57-69.

[3]. Yelnik A, Bonan I, Debray M, Lo E, Gelbert F, Bussel B. Changes in the execution of a complex manual task after ipsilateral ischemic cerebral hemispheric stroke. Arch Phys Med Rehabil 1996;77:806-810. 
[4]. Dee LH, Van Allen MW. Speed of decision-making processes in patients with unilateral cerebral disease. Arch Neurol 1973;28:163-6.

[5]. Elsass P, Hartelius H. Reaction time and brain disease: relations to location, etiology and progression of cerebral dysfunction. Acta Neurol Stand 1985; 71:11-9.

[6]. Vallar G, Bisiach E, Cerizza M, Rusconi ML. The role of the left hemisphere in decision-making. Cortex 1988;24:399-410.

[7]. Bouska MJ, Kiwatny E. Manual for Application of the Motor-Free Visual Perceptual Test to the Adult Population. 6th ed. Philadelphia, Pa: 1983.

[8]. Colarusso R, Hammill DD. MVPT. Motor Free Visual Perceptual Test. Novato, California: Academic Therapy Publication; 1972

[9]. Mercier L, Hébert R, Gauthier L. Motor Free Visual Perceptual Test: impact of verbal answer card position on hemispatial visual neglect. Occup Ther J Res. 1995;15:223-236.

[10]. Gauthier L, Dehaut F, Joanette Y. The Bell Test: a quantitative and qualitative test for visual neglect. Int J Clin Neuropsychol. 1989;11:49-54.

[11]. Teng EL, Chui HC. The Modified Mini-Mental State (3MS) Examination. J Clin Psychiatry. 1987;48:314318.

[12]. Folstein MF, Folstein SE, McHugh PR. 'Mini-Mental State': a practical method for grading the cognitive state of patients for the clinician. J Psychiatr Res. 1975;12:189-198.

[13]. Hébert R, Bravo G, Girouard D. Validation de l'adaptation française du Modified Mini-Mental State (3MS). Rev Gériatrie. 1992;17:443-450.

[14].Jumpei Takahashi, Toru Nishiyama, Yoshimasa Matsushima. Does grip strength on the unaffected side of patients with hemiparetic stroke reflect the strength of other ipsilateral muscles? J. Phys. Ther. Sci. 2017;29:64-66.
[15]. Suruliraj Karthikbabu, Mahabala Chakrapani. Hand-Held Dynamometer is a Reliable Tool to Measure Trunk Muscle Strength in Chronic Stroke. Journal of Clinical and Diagnostic Research. September 2017;11(9).

[16]. Kim SH, Pohl PS, Luchies CW, StylianouAP, Won Y. Ipsilateral deficits of targeted movements after stroke. Arch Phys Med Rehabil 2003;84:719-24.

[17]. Richard W Bohannon, Andrew Williams. Limb muscle strength is impaired bilaterally after stroke. J. Phys. Ther. Sci., 1995;10(7):1-7.

[18]. Johanne Desrosiers, Daniel Bourbonnais, Gina Bravo, Pierre-Michel Roy, Manon Guay. Performance of the 'Unaffected' Upper Extremity of Elderly Stroke Patient. Stroke. September 1996;27:1564-1570.

[19]. Nakayama H, Jorgensen HS, Raaschou HO, Olsen TS. Compensation in recovery of upper extremity function after stroke: the Copenhagen Stroke Study. Arch Phys Med Rehabil August 1994;75:852-7.

[20]. Turton A, Wroe S, Trepte N, Fraser C, Lemon RN. Contralateral and ipsilateral EMG responses to transcranial magnetic stimulation during recovery of arm and hand function after stroke. Electroenceph clin Neurophysiol 1996;101:316-328.

[21]. Netz J, Lammers T, Homberg V. Reorganization of motor output in the non-affected hemisphere after stroke. Brain 1997;120:1579-1586.

[22]. P. Manganottia, S. Patuzzoa, F. Corteseb, A. Palermoa, N. Smaniaa, A. Fiaschi. Motor disinhibition in affected and unaffected hemisphere in the early period of recovery after stroke. Clinical Neurophysiology 2002;113:936-943.

[22]. Heidi Johansen-Berg, Matthew F. S. Rushworth, Marko D. Bogdanovic, UdoKischka, Sunil Wimalaratna, Paul M. Matthews. The role of ipsilateral premotor cortex in hand movement after stroke. 2002;99(22):14518-14523.

How to cite this article:

Soumiya Selvarajan, Gajanan Bhalerao, Ashok K. Shyam, Parag Sancheti. IS THE UNAFFECTED SIDE OF STROKE PATIENTS ACTUALLY NORMAL?. Int J Physiother Res 2019;7(4):3135-3138. DOI: 10.16965/ijpr.2019.141 